\title{
MOTIVASI BELAJAR PADA SISWA ASLI PAPUA TERHADAP IMPLEMENTASI PENDIDIKAN KARAKTER
}

\author{
Anna Maria Anjaryani (1), Triana Noor Edwina ${ }^{(2)}$ \\ Fakultas Psikologi \\ Universitas Mercu Buana Yogyakarta \\ E-mail: anna53490@gmail.com
}

\begin{abstract}
Abstrak
Pendidikan memilki peran yang sangat penting untuk memenuhi sumber daya manusia yang memadai sebagai pendukung utama dalam pembangunan Indonesia. Pendidikan nasional berfungsi mengembangkan kemampuan dan membentuk karakter serta peradaban bangsa yang bermartabat dalam rangka mencerdaskan kehidupan bangsa. Sistem pendidikan di Indonesia telah dilakukan dari Sabang hingga Merauke Papua. Namun hingga saat ini masih menjadi tantangan dalam pemerataaan pendidikan yang ada di Indonesia. Belum adanya semangat pendidikan yang membebaskan, tidak berkembangnya kultur pendidikan yang sehat, dan belum terbentuknya masyarakat yang melek pendidikan. Kondisi politik yang tidak aman, ekonomi yang lemah, dan sekolah yang tidak memadai secara signifikan mempengaruhi pendidikan siswa Papua. Hal ini berpengaruh pada motivasi belajar dan menjadi salah satu penyebab rendahnya karakter pada masyarakat. Sehingga motivasi belajar pada siswa asli Papua memiliki pengaruh dalam implementasi pendidikan karakter.
\end{abstract}

Kata kunci: motivasi belajar, siswa asli Papua, pendidikan karakter

\begin{abstract}
Education has a very important role to fulfill adequate human resources as the main support in Indonesia's development. National education functions to develop abilities and shape the character and civilization of a dignified nation in the context of educating the life of the nation. The education system in Indonesia has been carried out from Sabang to Merauke Papua. But until now it is still a challenge in the equitable distribution of education in Indonesia. The absence of a liberating education spirit, the development of a healthy education culture, and the formation of a society that is not literate in education. Unsafe political conditions, a weak economy, and inadequate schooling significantly affect the education of Papuan students. This has an effect on learning motivation and is one of the causes of the low character of the community. So that motivation to learn in native Papuan students has an influence in the implementation of character education.
\end{abstract}

Keywords: learning motivation, native Papuan students, character education

Info Artikel

Diterima September 2019, disetujui Oktober 2019, diterbitkan Desember 2019

Dipublikasikan Oleh: Program Studi Bimbingan dan Konseling 


\section{PENDAHULUAN}

Pendidikan adalah investasi utama bagi penerus bangsa. Pendidikan merupakan alat yang menentukan untuk mencapai kemajuan dalam segala bidang penghidupan, dalam memilih dan membina hidup yang baik, yang sesuai dengan martabat manusia (Nurhidayah, 2015). Proses pendidikan dilakukan di seluruh wilayah Indonesia dari Kota Sabang di Provinsi Aceh sampai dengan Kota Merauke di Provinsi Papua, baik itu di wilayah perkotaan maupun pedesaan bahkan pendidikan juga dilakukan di daerahdaerah pedalaman. Salah satu yang menjadi tantangan untuk memajukan pendidikan di indonesia adalah menjangkau wilayah pedalaman karena pembangunan pendidikan yang bermutu dan merata di seluruh wilayah Indonesia merupakan cita-cita besar yang belum terwujud (Kompas.com, 2011).

Masalah-masalah pendidikan di indonesia diantaranya sarana, fasilitas dan tenaga pendidik yang kurang dan bermasalah, pendidikan kerap tidak menjangkau daerah terisolasi (Detiknews, 2018). Salah satu daerah di Indonesia yang ditetapkan sebagai daerah tertinggal adalah Papua (DetikNews, 2015). Papua merupakan salah satu daerah paling timur di Indonesia yang memiliki beragam keterbatasan pada kualitas pendidikan. Tiga masalah besar pendidikan di Papua, yaitu belum adanya semangat pendidikan yang membebaskan, tidak berkembangnya kultur pendidikan yang sehat, dan belum terbentuknya masyarakat yang melek pendidikan (Priharsanti, 2016). Semangat pendidikan masyarakat berkaitan dengan orang tua.

Rendahnya pendidikan yang disandang oleh orang tua menyebabkan tidak mampunya orang tua memberikan wawasan tentang pendidikan bagi anaknya, sehingga anak cenderung akan mengikuti metode yang dilakukan orang tuanya. Banyak anakanak yang tidak sekolah atau putus sekolah karena orang tua tidak memahami perkembangan pendidikan bagi anak (Mesmor, Rahamma, Unde, 2013). Hal ini juga berkaitan dengan faktor ekonomi orang tua. Kebanyakan pekerjaan orangtua siswa yang berasal dari pelosok daerah atau kampung adalah sebagai buruh tani dan nelayan, sehingga secara tidak langsung mempengaruhi motivasi belajar pada siswa. (Goo, 2017). Jika pendapatan orangtua rendah maka motivasi orangtua untuk menyekolahkan anak juga rendah. Apresiasi orangtua terhadap pendidikan dan lingkungan sosial juga mempengaruhi motivasi anak (Nurmalinda, Suntoro, Nurmalisa, 2017).

Tantangan yang dihadapi di Papua bukan mengatasi masalah persoalan jarak, kemiskinan, daya atau kekuatan yang cukup untuk terjadinya perbaikan, keterpencilan, atau isolasi, tetapi kebutuhan untuk menyadari atau mengakui ketidakmerataan yang terjadi dam membangun komitmen untuk mengatasi ketidakmerataan sambil memperbaiki mutu pendidikan, kesehatan, dan sektor sosial lainnya. Tantangan utama pembangunan di Papua dan Papua Barat berawal dari ketidakmerataan pendidikan antargenerasi anak-anak dan remaja Papua (Tim Education Sector Analytical and Capacity Development Partnership, 2014).

Siswa Papua kurang memahami pentingnya pendidikan dan esensi dari belajar. Hal ini menyebabkan kurangnya motivasi intrinsik pada siswa Papua. Sangat disadari karena kondisi sosial masyarakat, geografis, dan kondisi politik yang tidak mendukung sistem pendidikan di Papua. Kondisi politik yang tidak aman, ekonomi yang kemah, dan sekolah yang tidak memadai secara signifikan mempengaruhi pendidikan siswa Papua. Politik dan situasi ekonomi mempengaruhi prestasi pendidikan dan motivasi belajar siswa (Triyanto, 2019). Dibandingkan siswa lainnya, siswa Papua memiliki motivasi berdaya rendah. Siswa asli Papua kurang bertekad untuk menyelesaikan dan mencari strategi untuk memecahkan masalah, kemampuan bertarung, dan kurang kreatif 
terhadap pemecahan masalah. (Triyanto, 2019). Berdasarkan hasil wawancara, siswa Papua lebih terlihat mengalami permasalahan dalam motivasi belajar dibandingakan siswa non Papua.

Keterbatasan aksesbilitas dan insfrastuktur ini membuat kualitas masyarakat di pedalaman, khususnya di Papua masih sangat tertinggal dari pada masyarakat Indonesia pada umumnya. Sehingga hal ini berpengaruh pada motivasi belajar dan menjadi salah satu penyebab rendahnya karakter pada masyarakat. Tentunya kondisi tersebut tidak sesuai dengan kebutuhan saat ini dalam menyongsong MEA 2015. Dalam menyongsong MEA, negara-negara di wilayah ASEAN menempatkan peningkatan kualitas SDM, khususnya pembangunan pendidikan, sebagai prioritas nasional dalam Rencana Pembangunan Jangka Menengahnya. Diperlukan karakter yang kuat, terutama bagi daerah-daerah tertinggal, untuk dapat bersaing di era MEA (Wahyudi, Muzakki, Julliyansyah, 2016). Implementasi yang dapat dilakukan dalam hal ini adalah melalui pendidikan.

Implementasi pendidikan karakter menjadi penting dalam mempersiapkan generasi penerus bangsa. Pendidikan karakter diharapkan menjadi salah satu solusi untuk memecahkan persoalan bangsa dan negara Indonesia yang semakin lama semakin merosot karakternya. Padahal saat ini pendidikan karakter menjadi isu yang penting dalam dunia pendidikan. Pendidikan karakter menjadi isu penting sebagai upaya memperbaiki karakter generasi muda, karena degradasi moral yang terus menerus terjadi pada saat ini.

\section{PEMBAHASAN}

\section{Motivasi Belajar pada Siswa Asli Papua}

Berdasarkan hasil wawancara pada salah seorang guru di salah satu sekolah yang berada di Kabupaten Merauke Papua, mengungkapkan gambaran deskripsi mengenai motivasi belajar pada siswa asli Papua. Wawancara mengacu pada aspek motivasi belajar dari Sardirman (2011) yaitu berkaitan dengan aspek tekun menghadapi tugas. Berdasarkan hasil wawancara dengan seorang guru mengungkapkan bahwa ketika diberikan tugas di sekolah maupun pekerjaan rumah, siswa kerap kali terlihat kurang antusias dalam mengerjakannya. Pekerjaan rumah yang diberikan oleh guru, sering tidak dikerjakan. Siswa sering kali terlihat menyalin pekerjaan rumah milik teman yang lain saat pagi hari. Menurut penuturan salah seorang guru yang diwawancarai, siswa terlihat kurang memiliki daya juang dan semangat dalam pembelajaran yang diberikan, terutama ketika diberikan latihan-latihan soal. Ketika diberikan latihan soal, siswa seringkali menunggu jawaban yang dikerjakan oleh teman lain. Begitupun ketika ujian, siswa hanya menjawab asal-asalan. Hal ini menunjukan bahwa siswa kurang memiliki keuletan dalam menghadapi kesulitan.

Dalam menunjukan minat terhadap berbagai macam masalah, kebanyakan siswa asli Papua kurang menunjukan minat terhadap berbagai permasalahan yang berkaitan dengan mata pelajaran di dalam kelas. Namun siswa cenderung lebih tertarik terhadap aktivitas fisik di luar kelas, seperti mata pelajaran olahraga atau kesenian. Begitu pula dalam menunjukan kemandirian dalam bekerja. Menurut penuturan salah seorang guru, ketika guru memberikan latihan soal atau tugas rumah, siswa jarang mengerjakannya secara mandiri, siswa mengerjakan berkelompok bersama dengan teman sekelas yang dianggap lebih pandai. Pada saat diberikan tugas-tugas rutin, siswa pun jarang mengerjakannya. Ketika mempertahankan pendapatnya, siswa kebanyakan kurang antusias dalam mengikuti pembelajaran akademik di kelas, sehingga siswa pun jarang 
mengemukakan pendapatnya atau berdiskusi mengenai pembelajaran di dalam kelas. Pada saat pembelajaran berlangsung di kelas dan saat diskusi sedang berlangsung, siswa juga jarang mengeluarkan pendapatnya. Siswa terlihat lebih banyak berdiam. Sehingga dapat dikatakan siswa jarang berdiskusi untuk mengeluarkan pendapatnya, dan lebih banyak berdiam. Siswa asli Papua juga kebanyakan kurang menyukai pembelajaran akademik, sehingga siswa tergolong pasif dalam kegiatan pembelajaran. Siswa harus dibantu untuk mengerjakan tugasnya.

\section{Motivasi Belajar Siswa Asli Papua dan Implementasi Terhadap Pendidikan Karakter}

Pendidikan karakter merupakan berbagai usaha yang dilakukan oleh berbagai personil sekolah, bahkan yang dilakukan bersama-sama dengan orang tua dan anggota masyarakat untuk membantu anak-anak dan remaja agar menjadi atau memiliki sifat peduli, berpendirian, dan bertanggung jawab (Daryanto, 2013). Menurut Kementerian Pendidikan Nasional (2010) pendidikan karakter dimaknai sebagai pendidikan yang mengembangkan dan karakter bangsa pada diri peserta didik sehingga mereka memiliki nilai dan karakter sebagai karakter dirinya, menerapkan nilai-nilai tersebut dalam kehidupan dirinya, sebagai anggota masyarakat, dan warganegara yang religius, nasionalis, produktif dan kreatif. Pendidikan karakter pada intinya bertujuan membentuk bangsa yang tangguh, kompetitif, berakhlak mulia, bermoral, bertoleran, bergotong royong, berjiwa patriotik, berkembang dinamis, berorientasi ilmu pengetahuan dan teknologi yang semuanya dijiwai oleh iman dan takwa kepada Tuhan Yang Esa berdasarkan pancasila.

Nilai-nilai pendidikan karakter bangsa yang bersumber dari hal-hal di atas adalah sebagai berikut : 1) Religius, 2) Jujur, 3) Toleransi, 4) Disiplin, 5) Kerja Keras, 6) Kreatif, 7) Mandiri, 8) Demokratis, 9) Rasa Ingin Tahu, 10) Semangat Kebangsaan, 11) Cinta Tanah Air, 12) Menghargai Prestasi, 13) Bersahabat/Komunikatif, 14) Cinta Damai, 15) Gemar Membaca, 16) Peduli Lingkungan, 17) Peduli Sosial, dan 18) Tanggung jawab.

Pendidikan karakter diarahkan untuk memberikan tekanan pada nilai-nilai tertentu seperti rasa hormat, tanggungjawab, jujur, peduli, dan adil dan membantu siswa untuk memahami, memperhatikan, dan melakukan nilai-nilai tersebut dalam kehidupan mereka sendiri untuk mencapai kesuksesan hidup. Motivasi dipandang sebagai dorongan mental yang mendorong dan mengarahkan perilaku manusia, termasuk perilaku belajar. Penerapan pembelajaran karakter dalam dunia pendidikan di dukung motivasi belajar yang tinggi akan sangat berpengaruh pada hasil belajar, terlebih apabila didukung sarana pembelajaran yang mencukupi, karena sesuai dengan apa yang dibutuhkan oleh peserta didik (Mugiono, 2017).

Motivasi belajar menjadi salah satu faktor yang mendukung dalam mengimplementasikan pendidikan karakter bagi siswa. Nilai-nilai pendidikan karakter yang belum tercerminkan pada siswa Papua. Salah satunya adalah kerja keras yang masih minim di temukan pada siswa asli Papua. Hal ini dapat dilihat dengan kurangnya daya juang dan keuletan pada siswa asli Papua terhadap pembelajaran di sekolah. Saat kegiatan pembelajaran siswa terlihat malas dan kurang aktif. Bahkan pada saat ada tugas maupun ujian mereka tidak pernah belajar sebelumnya, karena memang tidak ada buku yang mereka miliki. Kebiasaan siswa yang tidak sungguh-sungguh dalam menjawab soal maupun pertanyaan, serta banyaknya siswa yang tidak mengerjakan tugas maupun pekerjaan rumah. Selain itu rendahnya kreatifitas, minat membaca, dan 
sikap disipilin juga masih terlihat pada siswa asli Papua (Wahyudi, Muzakki, Julliyansyah, 2016).

Berdasarkan hasil penelitian yang dilakukan oleh Mugiono (2017) mengungkapkan bahwa terdapat pengaruh yang positif dan signifikan antara pendidikan karakter, sumber belajar dan motivasi belajar, secara sama-sama atau secara regresi terhadap hasil belajar bidang studi IPS siswa kelas VIII SMPN I Gondang Tulungagung pada tahun ajaran 2016/2017. Pengaruh positif memberi pengertian bahwa semakin bagus hasil pendidikan karakter pada siswa, semakin cukup ketersediaan sumber belajar, dan semakin baik motivasi belajar, akan semakin berpengaruh terhadap hasil belajar siswa kelas VIII SMPN I Gondang pada bidang studi IPS.

Penelitian yang dilakukan oleh Firmansyah, Wahyuni, Gumanti (2017) mengungkapkan hasil bahwa pendidikan karakter berpengaruh signifikan terhadap motivasi belajar siswa kelas X Tata Niaga di SMK E Adi Karya Kabupaten Pesisir Selatan. Pendidikan karakter memiliki korelasi positif pada keberhasilan akademik siswa dalam proses pembelajaran di sekolah. Peningkatan motivasi siswa sekolah dalam meraih prestasi akademik ditunjukkan oleh sekolah yang menerapkan pendidikan karakter, adanya penurunan drastis pada perilaku negatif siswa yang dapat menghambat keberhasilan akademik. Berdasarkan kajian di atas menunjukkan bahwa pentingnya pengaruh motivasi belajar pada siswa asli Papua sebagai implementasi dari pendidikan karakter.

\section{KESIMPULAN}

Berdasarkan latar belakang masalah dan pembahasan di atas penulis menyimpulkan bahwa motivasi belajar pada siswa asli Papua berpengaruh terhadap implementasi pendidikan karakter. Hal ini ditunjukkan melalui beberapa hasil penelitian yang mengungkapkan bahwa terdapat pengaruh yang positif dan signifikan antara pendidikan karakter, sumber belajar dan motivasi belajar, secara sama-sama atau secara regresi terhadap hasil belajar (Mugiono, 2017). Serta penelitian Firmansyah, Wahyuni, Gumanti (2017), yang mengungkapkan bahwa pendidikan karakter berpengaruh signifikan terhadap motivasi belajar siswa. Selaras dengan nilai-nilai yang terkandung dalam pendidikan karakter yang sesuai dengan aspek-aspek motivasi belajar. Implementasi Pendidikan Karakter diharapkan dapat meminimalisir dan mengatasi permasalahan terkait degradasi moral yang terjadi pada diri siswa, sehingga dapat berpengaruh dalam peningkatan motivasi belajar pada siswa asli Papua.

\section{DAFTAR PUSTAKA}

Daryanto, d. (2013). Implementasi Pendidikan Karakter di Sekolah. Yogyakarta: Gava Media

Departemen Pendidikan Nasional (2010). Pendidikan Karakter Teori \& Aplikasi. Jakarta: Direktorat Jenderal Manajemen Pendidikan dan Menengah Kementerian Pendidikan Nasional

Desmita. (2017). Psikologi Perkembangan Peserta Didik; Panduan Bagi Orang Tua dan Guru dalam Memahami Psikologi Anak, Usia SD, SMP, dan SMA. Bandung: Resmaja Rosdakarya 
Firmansyah, Wahyuni, Gumanti (2017). Pengaruh Pendidikan Karakter, Lingkungan Sekolah dan Motivasi Terhadap Hasil Belajar Siswa Kelas X Tata Niaga Di SMKE Adi Karya Kabupaten Pesisir Selatan. Jurnal STKIP PGRI Sumatera Barat.

Goo. (2017). Pengaruh Perhatian Orangtua dan Motivasi Belajar Terhadap Prestasi Belajar Dalam Bidang Ekonomi Kelas X SMA YPK Tabernakel Nabire Papua Tahun Ajaran 2017/2018. (Skripsi tidak diterbitkan) Fakultas Ekonomi. Jurusan Pendidikan Ekonomi. Universitas Negeri Semarang.

Kompas 2011. Suram Pendidikan Untuk Semua. Di unduh https://lifestyle.kompas.com/read/2011/03/02/19062358/suram.pendidikan.untuk.s emua. Tanggal 25 Oktober 2018

Mesmor, Rahamma dan Unde (2013). Pemahaman Orang Tua Tentang Informasi Program Wajib Belajar Pendidkan Dasar Dalam Memotivasi Anak Suku Malind Untuk Belajar di Kabupaten Merauke. Jurnal Komunikasi KAREBA, 2(3), 234240 .

Mugiono (2017). Pengaruh Pendidikan Karakter, Sumber Belajar dan Motivasi Belajar Terhadap Hasil Belajar Siswa Bidang Studi IPS. Jurnal (STKIP) Sekolah Tinggi Keguruan dan Ilmu Pendidikan PGRI Tulungagung

Nurmalinda., Suntoro., \& Nurmalisa. (2017). Pengaruh Tingkat Ekonomi Keluarga dan Motivasi Menyekolahkan Anak Terhadap Angka Putus Sekolah di Kelurahan Kupang Teba Kota Bandar Lampung. (Skripsi tidak dipublikasikan) Fakultas Keguruan dan Ilmu Pendidikan. Universitas Lampung. Lampung.

Sardiman, A.M. (2011). Interaksi \& Motivasi Belajar Mengajar. Jakarta: PT. Raja Grafindo Persada.

Triyanto. (2019). The Academic Motivation of Papuan Students in Sebelas Maret University Indonesia. journals.sagepub.com/home/sgo. 1-7.

Uno, H. (2007). Model Pembelajaran Menciptakan Proses Belajar Mengajar yang Kreatif dan Efektif. Jakarta: Bumi Aksara.

Wahyudi., Muzakki., Julliyansyah., (2016). Pembelajaran Berbasis Karakter untuk Meningkatkan Daya Saing Dalam Era Global Bagi Siswa Di Daerah Terdepan, Terluar dan Tertinggal (Studi Kasus di Kalimantan Utara, Sulawesi Utara, NTT, dan Papua). Jurnal Teori dan Praksis Pembelajaran IP, 1(1), 1-12. 